\title{
Wordplay in English Online News Headlines
}

\author{
Roya Monsefi (Corresponding author) \\ School of Languages, Literacies and Translation, Universiti Sains Malaysia, \\ 11800 USM, Penang, Malaysia \\ E-mail: rm10_pbt007@student.usm.my \\ Tengku Sepora Tengku Mahadi \\ School of Languages, Literacies and Translation, Universiti Sains Malaysia, \\ 11800 USM, Penang, Malaysia \\ E-mail: tsepora@usm.my
}

Doi:10.7575/aiac.alls.v.7n.2p.68

URL: http://dx.doi.org/10.7575/aiac.alls.v.7n.2p.68
Received: $12 / 11 / 2015$

Accepted: 16/01/2016

\begin{abstract}
Within the endless stream of information available on the news media market, news headline language is characterised by several linguistic, pragmatic, rhetorical and functional features that distinguish it from other varieties of language that are not specialised. In the present study, the rhetorical features of English news headlines, through wordplay investigation, using a sample of 100 headlines were studied. Wordplay is investigated because it leads to the persuasiveness of message that is sometimes so subtle that the readers might not even recognise it. A taxonomy of wordplays was constructed according to Leigh's (1994) model which made it possible to access a comprehensive checklist. The way the persuasive element, i.e. wordplay, was presented for the English headline readers was examined using the descriptive method and in light of textual rhetorical analysis. The outcome of the study suggests that English news headlines are likely to contain one or more clearly defined wordplay. The most frequent wordplay is that of tropes or more specifically metonymy. However, there are some wordplays such as polysyndeton, anadiplosis, antimetabole, epistrophe and polyptoton that are absent in English headlines. The majority of unused categories fall under the category of schemes.
\end{abstract}

Keywords: wordplay, news headlines, schemes, tropes, rhetoric

\section{Introduction}

In such a world where, as Sandell (1977) and Oaks (2012) remarked, mass communication have a crucial part in shaping attitudes, opinions, events and objects, the wording of the message may be the most important factor in persuading the recipient to adopt a particular point of view. Ungerer (2000) argued that for successfully communicating the message, all texts must seduce their audience. They must urge the potential reader into reading and into accepting the message. No surprise that media texts are saturated with strategies to win the audience and maintain the impression. Accordingly, it seems likely that wordplay (rhetorical figures of speech) may be used in news headlines for attracting readers to read the whole article, and ultimately persuading in accepting or rejecting a particular opinion.

Headlines are usually written by different people from those who write the main bodies of the news texts (Bell, 1991). Accordingly, Dor (2003) mentioned that news editors and copy editors usually dictate the choice of headlines for specific news stories. As a journalist, editor and linguist, Bell (1991) asserted that headlines are a "part of news rhetoric whose function is to attract the reader." (p.189). Saxena (2006) claimed that skilled copy editors devote noticeable time to write headlines because they know that "dead and dull headlines drive readers away from good news reports." (p. 17). Given that one of the main functions of headlines is "persuasion" and with considering the fact that "wordplay" is generally a significant means of persuasion, wordplay investigation in English news headlines is the salient issue that counts throughout this study.

\section{Statement of the Problem and Research Methodology}

Iarovici and Amel (1989) claimed that both headline strategy and advertising strategy seek to bring about desire. In the case of headline the desire is to read the whole article; and with regard to advertisement the desire is to purchase the product.

Ali (2009) mentioned that the headline writer has the purpose of capturing the readers' emotion with as few words as possible. She claimed that the language of news presents factual content of the story as well as emotional tone. This emotional tone is mostly achieved through wordplay. However, "its role in headline writing and translation has largely escaped the attention of scholars and researchers." (p. 33). It has been mentioned that wordplay has an effect in persuasiveness and attractiveness of message. However, the problem rises finding the answer to the regularity that they appear at news headlines. Regarding the present corpus, some categories of wordplay might frequently appear in 
English news headlines while others might seldom show themselves. On the other hand, headline writers might be reluctant even in using any kinds of wordplay and show preference in using straightforward headlines.

Detecting wordplays in news headlines and the intention behind their use is not an easy task. Because, as van Dijk (1988) claimed, "news discourse will leave much information implicit, either because it is generally known and can be inferred by any reader of the same culture or because it is a possible inference the journalist does not want to make openly" (p. 107). van Dijk (1988) maintained that often, from a critical point of view, what is not directly mentioned is even more important than what is explicitly expressed and meant.

The data for the present study is extracted from Euronews website with international influence. The analysis of wordplay is conducted using textual analysis and rhetorical theory. Leigh (1994) offered a taxonomy for classifying wordplay that can help the present study in making a checklist of different wordplay types in news headlines. His model is encapsulated in the following figure:

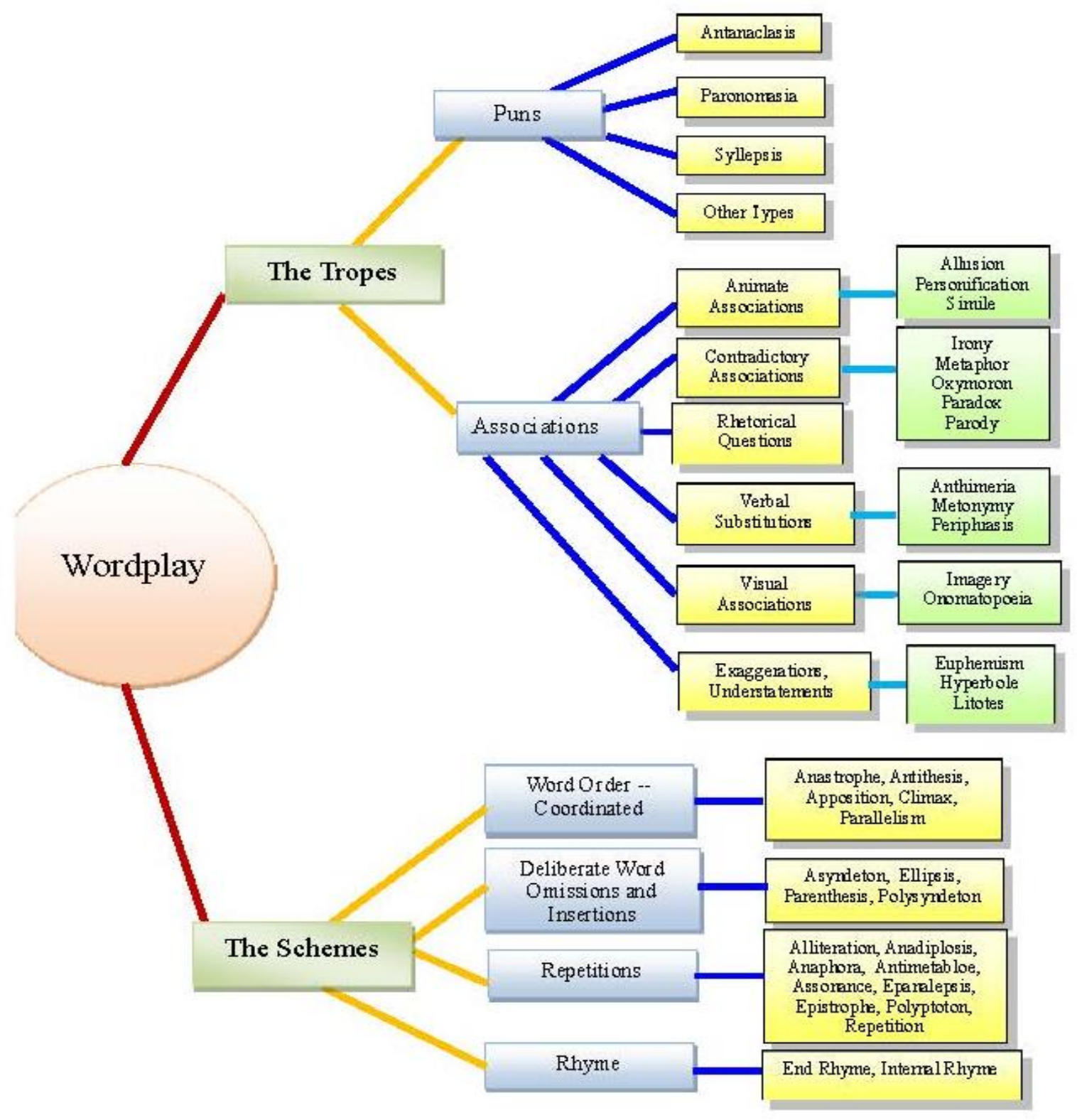

Figure 2.1 Taxonomy of wordplay (figures of speech). (Adopted from Leigh, 1994)

Wordplay encompasses two major groups of tropes and schemes. The tropes, which involve the play on the meaning of words, are divided into puns and associations and their related subcategories. The schemes, which involve the play on grammar and the change in word order or pattern, consist of word order--coordinated, deliberate word omissions and insertions, repetitions and rhyme. These four categories are sub-divided into their related subcategories. The overall number of the scheme's subcategories is 20.

\section{Results and Discussion}

Ninety-seven percent of the 100 selected Euronews "English" news headlines have one or more clearly defined wordplay. These results suggest that Euronews English language copy editors are likely to engage their headlines with wordplays. However, it should be mentioned that they were moderate in using wordplays and headlines with the low mid-range set of wordplays in them; i.e. 3 wordplays, have been found to be used with highest frequency. 
Across the selected headlines, there is a preference for the use of tropes, namely metonymy, rather than schemes. Furthermore, there is no usage of oxymoron, parody, anthimeria, rhetorical questions, antithesis, climax, parenthesis, polysyndeton, anadiplosis, antimetabole, assonance, epanalepsis, epistrophe, polyptoton, repetition and end rhyme in them. The majority of unused wordplays belonged to the schemes category. In their study of advertising headlines, Leigh (1994) and Smith $(2002,2006)$ discovered a similar phenomenon, where some wordplays occurred frequently and others seldom. It can be suggested that certain wordplays are more suited to headline copy.

One instance of English news headlines analysed in this study, contains the majority of wordplays, i.e. eight. It will be discussed below:

\section{Iran, Iraq back Syria peace plan, Annan says}

UN and Arab League envoy on Syria Kofi Annan said on Wednesday that both Iran and Iraq back his peace plan to end the 17-month standoff between President Bashar Assad's regime and the opposition. Returning from a visit to the region after meetings with officials in Damascus, Baghdad and Tehran, Annan said both nations could play a key role in shaping a transitional government. "In both Iran and Iraq, the governments committed to supporting the six point plan. They supported the idea of political transition, which will be Syrian-led," Annan told the Security Council via video link from Geneva. But Damascus says Annan's plan is failing because the international community is turning a blind eye to countries supplying weapons to anti-Assad rebels. Bashar Ja'afari, Syrian ambassador to the UN, said: that "without putting an end to the funding and arming of the armed groups in Syria, it will be very difficult to see the plan of Mr. Kofi Annan succeeding on the spot."

Annan's peace plan was approved by the UN Security Council and accepted by Syria in March. It called for an immediate ceasefire and withdrawal of heavy weapons from populated areas by the Syrian government. But the April 12 ceasefire agreement has failed to take hold.

One of the instances of figurative language in the English headline above is the "metonymic" use of countries, i.e. Iran, Iraq and Syria. Place-name based metonymies are employed in order to conceptually represent Iran, Iraq and Syria's government officials: Both Iranian and Iraqi government officials supported the Syrian-official-led peace plan. The metonymic use of place names preserves spatial value in headlines. Place-name metonymies trigger a whole-part relationship in which if as an entity the country is considered as a "whole", the government officials of that country are considered as a "part" of that entity. Hence, the responsibility for political actions can be attributed to the country as a whole. Accordingly, metonymy has a crucial impact on the construction of stereotypes. They are connected with the country when the discourse itself focuses on the country instead of individuals.

The metonymic use of countries also leads to the trope "personification". The human trait of "backing" is attributed to inanimate entities; i.e. Iran and Iraq in Iran, Iraq back Syria peace plan. On the other hand, having a peace plan is attributed to Syria which creates another instance of personification. As the subsequent findings also reveal, news headlines have a tendency to personify the name of countries in order to project the final result as the consequence of country's action as a whole.

Considering schemes, the English headline contains one instance of "anastrophe", "asyndeton" and "ellipsis". The change in the syntactically correct order of subject, object and verb creates anastrophe. The normal sequence of words in English is subject followed by verb, and then object. The inversion of the normal word order in Iran, Iraq back Syria peace plan, Annan $\underline{\text { Says }}$ is for creating an effect and bringing Iran and Iraq's support into focus.

The deliberate omission of conjunction "and" in Iran, Iraq back Syria creates asyndeton which is used for achieving brevity in the headline. Asyndeton can speed up the rhythm and make a single idea more memorable.

Finally, the omission of possessive "s" creates the last scheme in the English headline, i.e. ellipsis. It can be recovered as in: Iran, Iraq back Syria's peace plan. Ellipsis does not alter the original meaning of headline. It just condenses the lexical units for preserving space and brevity.

In order to better elucidate the wordplays, the following table is presented:

Table 3.1 The wordplay employed on the English headline

\begin{tabular}{lc}
\hline \multicolumn{2}{c}{ Wordplay } \\
\hline Schemes & Tropes \\
\hline Anastrophe $\rightarrow$ Annan says & Personification $(2) \rightarrow$ Iran, Iraq back / Syria peace plan \\
Asyndeton $\rightarrow$ Iran Iraq & Metonymy $(3) \rightarrow$ Iran / Iraq / Syria \\
Ellipsis $\rightarrow$ Syria peace plan &
\end{tabular}

Generally, in all the one hundred headlines analysed in the present study, seven instances of English headlines have six wordplays which include the second-largest set of wordplay.

Ten instances of English headlines contain five wordplays which include the third-largest set of wordplays.

Fourteen instances of English headlines have four wordplays which include the high mid-range set of wordplays; and twenty-seven instances of English headlines have three wordplays which include the low mid-range set of wordplays.

Twenty two instances of English headlines have two wordplays which include the second-lowest set of wordplay in headlines. 
Sixteen instances of English news headlines contain the minority of wordplays; i.e. only one.

And, finally, three instances of English news headlines are the straightforward plain headlines with no wordplay in them.

In order to better encapsulate the distribution of wordplays in 100 English news headlines of Euronews, the following Table 3.2 and column chart (Figure 3.1) are presented.

In non-algebraic terms, the percentage is found by taking the number of occurrences of an event (one wordplay), dividing by the total instances of wordplays examined, and multiplying by one hundred percent:

$$
\text { Percentage }=\frac{\text { Number of Occurrence }}{\text { Total Number }} \times 100
$$

Example:

Number of occurrence of pun

Percentage of pun in 100 English News Headlines $=\frac{3}{297} \times 100=1.01 \%$

Total number of wordplay occurrence

Table 3.2 The sum of the frequencies of wordplays in 100 English news headlines

\begin{tabular}{|c|c|c|}
\hline Wordplay Category & Frequency & Percentage \\
\hline Pun & 3 & $1.01 \%$ \\
\hline Allusion & 9 & $3.03 \%$ \\
\hline Personification & 52 & $17.51 \%$ \\
\hline Simile & 1 & $0.34 \%$ \\
\hline Irony & 1 & $0.34 \%$ \\
\hline Metaphor & 17 & $5.72 \%$ \\
\hline Oxymoron & 0 & $0 \%$ \\
\hline Paradox & 1 & $0.34 \%$ \\
\hline Parody & 0 & $0 \%$ \\
\hline Anthimeria & 0 & $0 \%$ \\
\hline Metonymy & 98 & $32.99 \%$ \\
\hline Periphrasis & 0 & $0 \%$ \\
\hline Imagery & 1 & $0.34 \%$ \\
\hline Onomatopoeia & 1 & $0.34 \%$ \\
\hline Euphemism & 2 & $0.67 \%$ \\
\hline Hyperbole & 15 & $5.05 \%$ \\
\hline Litotes & 2 & $0.67 \%$ \\
\hline Rhetorical Questions & 0 & $0 \%$ \\
\hline Anastrophe & 3 & $1.01 \%$ \\
\hline Antithesis & 0 & $0 \%$ \\
\hline Apposition & 6 & $2.02 \%$ \\
\hline Climax & 0 & $0 \%$ \\
\hline Parallelism & 3 & $1.01 \%$ \\
\hline Asyndeton & 3 & $1.01 \%$ \\
\hline Ellipsis & 67 & $22.56 \%$ \\
\hline Parenthesis & 0 & $0 \%$ \\
\hline Polysyndeton & 0 & $0 \%$ \\
\hline Alliteration & 8 & $2.69 \%$ \\
\hline Anadiplosis & 0 & $0 \%$ \\
\hline Anaphora & 0 & $0 \%$ \\
\hline Antimetabole & 0 & $0 \%$ \\
\hline Assonance & 0 & $0 \%$ \\
\hline Epanalepsis & 0 & $0 \%$ \\
\hline Epistrophe & 0 & $0 \%$ \\
\hline Polyptoton & 0 & $0 \%$ \\
\hline Repetition & 0 & $0 \%$ \\
\hline End Rhyme & 0 & $0 \%$ \\
\hline Internal Rhyme & 4 & $1.35 \%$ \\
\hline Sum & 297 & $100 \%$ \\
\hline
\end{tabular}




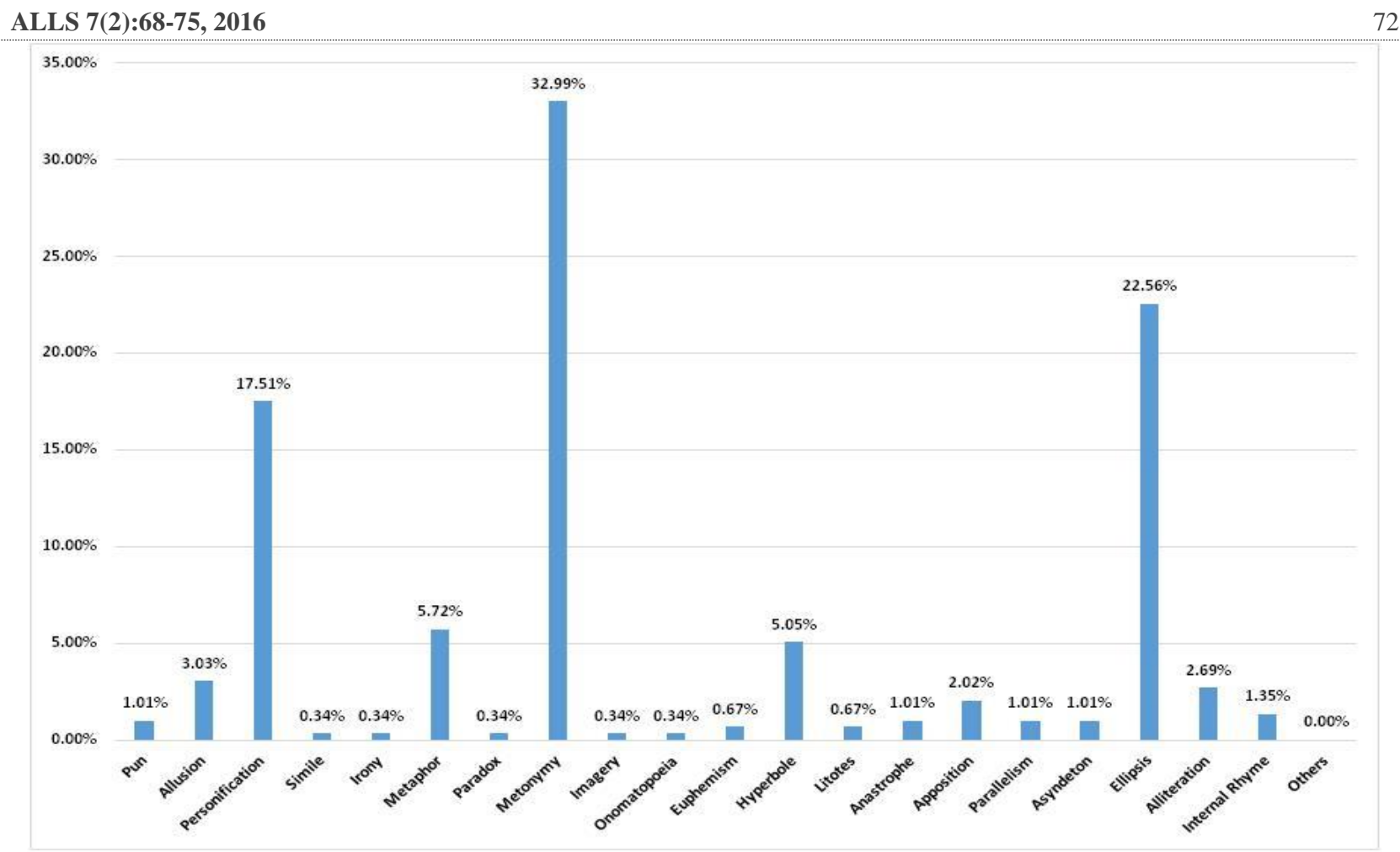

Figure 3.1 The distributions of wordplays in 100 English news headlines

From the total number of 297 instances that wordplay occurred in 100 English news headlines, below the wordplay categories are arranged from the most frequent to the least in the descending order which provides the answer for the research question:

Metonymy 98 (32.99\%), Ellipsis 67 (22.56\%), Personification 52 (17.51\%), Metaphor 17 (5.72\%), Hyperbole 15 (5.05\%), Allusion 9 (3.03\%), Alliteration 8 (2.69\%), Apposition 6 (2.02\%), Internal Rhyme 4 (1.35\%), Anastrophe, Asyndeton, Parallelism and Pun 3 (1.01\%), Litotes and Euphemism 2 (0.67\%), Paradox, Irony Simile, Imagery and Onomatopoeia $1(0.34 \%)$ and no instances of Oxymoron, Parody, Anthimeria, Periphrasis, Rhetorical Questions, Antithesis, climax, Parenthesis, Polysyndeton, Anadiplosis, Anaphora, Antimetabole, Assonance, Epanalepsis, Epistrophe, Polyptoton, Repetition and End Rhyme. The latter group fall under the category of others in the above column chart (0 frequencies).

The largest portion belongs to "Metonymy" which falls under the category of Tropes and the smallest to Oxymoron, Parody, Anthimeria, Periphrasis, Rhetorical Questions, Antithesis, climax, Parenthesis, Polysyndeton, Anadiplosis, Anaphora, Antimetabole, Assonance, Epanalepsis, Epistrophe, Polyptoton, Repetition and End Rhyme in which the first five fall under the category of Tropes and the remaining 13 fall under the category of Schemes. Overall, the occurrences of tropes were much higher than Schemes. This finding is in line with Smith's $(2002,2006)$ studies of English-language printed advertisements who concluded that the wordplays used in his selected advertising headlines were more of trope category than the schemes.

In a contrastive study conducted by Bonyadi and Samuel (2013), the rhetorical devices in the 20 editorial headlines of English newspaper, The New York Times and those of Persian newspaper, Tehran Times were studied. Their study is mentioned here to emphasise the similarity in findings. The most frequent wordplay that emerged in Bonyadi and Samuel's study in both English and Persian news headlines was "metonymy" which is in line with the results of the present research which can lead to the conclusion that copy editors favored using this wordplay the most.

The result of the research question has confirmed Newmark's (1988) claim that seldom has a text exclusively one function (e.g. informative function) and in the majority of cases the two or more functions (e.g. expressive, informative and vocative functions) are intermingled in a text with an emphasis on one. Euronews headlines were no different and besides being informative, they were saturated in wordplays. Particularly, the trope metonymy's dominant position in headlines was remarkable.

Metonymy in Leigh's (1994) term is substituting the name of an attribute for what is actually meant. Metonymy has basically a referential function; i.e. it allows one entity to stand for another. Since with metonymy one concept stands for another while both concepts are actually activated at least to some degree, metonymy can be considered as an effective mental shortcut; i.e. expressing two things for the price of one.

One particular type of metonymy, namely capital / country for government metonymy (from the capital / country as the metonymic source towards government as a metonymic target) was frequent in English and Persian news headlines. Referring to the result of the study it can be concluded that, at least in theory, any capital / country can be considered as a viable metonymic source. The content and context of the news story determined specifically the entity that the capital 
/ country name referred to; i.e. if the whole government, just a ministry, or some other institution, legal, economic or otherwise was actually meant.

Example:

Amsterdam tries to get round coffee-shop tourist ban

Referring to the news text, Amsterdam's last year's government introduced a ban which barred the tourists from marijuana-selling coffee shops. However, Amsterdam's mayor intended to get round the law for his city because ninety percent of revenues would be lost if foreigners could not let in. The headline represented the social actor impersonally by means of reference to a place with which he was, in the given context, closely associated. Using this type of metonymy, the representational choice is manifested in a way to exclude social actors in relation to a given action. Then, the social actors are pushed into backgrounds and mentioned later in the news text, but they are not deemphasised. Doing so, the headline attempts to exclude the social actor of any possible criticism. On the other hand, in headlines such as "Merkel praises Greek reform and promises support" the social actor is being brought in the spotlight. All the emphasis is put on Merkel though she was not the only one who decided to support Greek's reform. In fact, the proper name stands for the German government as a whole with Merkel on top of it. The headline holds Merkel thoroughly accountable for imposing pressure on Greece for its austerity measures.

The second and third most frequent wordplays in the English headlines were the scheme ellipsis and the trope personification; respectively. Leigh (1994) defined ellipsis as the intentional omission of a word or words that can often be provided by referring to the context. Brevity is the soul of wit in news headlines and a short, attention-grabbing headline counts a lot for a news article because headlines have to maximise information output and minimise space. For instance in the headline Military past and present protest Portugal's 2013 budget, certain lexical units of the headline is omitted in order to meet space constraints and present immediate and quick information. The omitted words are recoverable from the context as in: Military of Portugal's past and present members protested at Portugal's 2013 budget. Furthermore, one of the instances of ellipsis in the headlines that above saving the space had specific pragmatic function was the omission of auxiliaries in the passive headlines as in:

\section{Journalist killed in southern Russia \\ Ghana presidential vote extended by a day \\ Obama named Time magazine's Person of 2012 \\ Five $\underline{\text { killed }}$ in Moscow shooting}

The above-mentioned headlines made the actors who killed the journalist in southern Russia, extended Ghana presidential vote, named Obama as Time magazine's Person of 2012 and killed five people in Moscow shooting unclear to the reader(s). The headlines used passive voice to emphasise the act itself without mentioning the actors involved in the act which makes it possible for the journalists to evade the role of responsible actors and which in a way makes it difficult for the reader(s) to judge about the perpetrator of an action. As the unique constraint of headline grammar, auxiliaries are omitted in passive structures to make the headlines more assertive.

Personification, the third most frequent wordplay in English news headlines, is used to add dramatic power to inanimate objects or abstract notions. It emotionally connects the readers with the object that is personified which in a way makes the readers feel empathy or sympathy for that idea or object. The tendency to personify the name of the countries was seen in the majority of news headlines in the corpus. For instance,
Israel fires on militants in Gaza strip
Turkey closes airspace to Syrian aircraft
UK to reduce Afghanistan troop numbers

The concept of the country mentioned as an autonomous individual made it convenient for copy editors to save space in the news headlines by allowing the attribution of action to single individual agents. In addition, personification blurred and disguised the role of actual people responsible for the actions described.

The fourth most frequent wordplay in English news headlines was metaphor. It was used to structure an abstract, more complex and fuzzy concept in terms of a concrete, more familiar concept. For instance
Flag raising error stirs anger in Portugal
Georgian dream leader looks to mend ties with Moscow
Israel fires on militants in Gaza strip

Application of metaphor facilitated discourse by underpinning the cognitive function of conceptualising. The use of above lexical units stirring anger, mending ties, and firing militants in headlines allows the reader greater understanding 
of the concept being described by comparing it to an item that is more familiar to the reader. Metaphoric words extended the meaning by providing two or more ideas for one which can leave a lasting impression on readers' minds.

Hyperbole, the fifth most frequent wordplay in English news headlines, was used to make deliberate exaggerations for making rhetorical effect. For instance, in the headlines

Cash crunch for Greece in November

Protesters angry at Spain's “hunger budget”

Hyperbole is used as a warning to the political parties about the country's deplorable financial conditions in order to emphasise the seriousness of the situation and the urgency for action.

Or in the headline

\section{As Europe suffers, America stands by}

Hyperbole is used in order to criticise America and its indifference towards Europe suffering. And in the headline

\section{No White House for Romney}

Hyperbole is used to belittle Romney and his political party with initiating the headline with strong negation. Hyperbolic headlines can change the emotional state of readers to approve or disapprove an action or a character.

Allusion was the sixth most frequent wordplay in English news headlines which is the incidental mention of an event, place, person or thing, either directly or by implication. For instance in the headline:

\section{Kenyans win torture case against British government}

The alluding unit torture case referred to the brutal British Empire- era abuse in which thousands of Kenyans were tortured during an anti-colonial uprising in the 1950s. The use of allusion was significant for the economy of space in headline and could remind the readers of pertinent event latent in the headline. It made it possible for headline writers to better convey the message by associating the readers' emotions in the word "torture". In the allusive headlines examined in the corpus, allusion also permitted the copy editors to imply something which if explicitly mentioned could seem libellous.

Alliteration, the seventh most frequent wordplay in English news headlines, was used to draw readers' attention to certain words and make those words stand out in order to create a particular concept. Apposition, a structure in which a noun or phrase used alongside another noun or phrase as an explanatory equivalent, was the eighth most frequent wordplay in English news headlines. It was mainly used as a guide to help the readers' in the interpretation of a message and to minimizing the ambiguity.

Internal Rhyme, the ninth most frequent wordplay in English news headlines, enhanced the musical effects of headlines and made it possible for the copy editors to provide the headlines with rhythm and emphasis.

Pun, anastrophe, parallelism and asyndeton were the $10^{\text {th }}$ most frequent wordplays in English news headlines. Pun added brevity and profound meanings to the news headline by providing semantic links; anastrophe, by deviating the normal word order, was used for adding extra emphasis; parallelism added rhythm to the headline and created balanced and smoother flow of ideas; and finally asyndeton provided the implied meaning in a succinct form by eliminating the conjunctions.

Euphemism and Litotes were the $11^{\text {th }}$ most frequent wordplays in English news headlines. Euphemism was used in preventing face loss, observing general social mores and showing solidarity with the referent. Litotes, on the other hand, was used as an ironical understatement in which the real identity of addresses was blurred in order to either hide the potential implications or to divert readers' attention to certain points; i.e. decreasing the real identity of social actors to increase attention and sympathy towards them.

Simile, Irony, Paradox, Imagery and Onomatopoeia were overall the $12^{\text {th }}$ most frequent wordplays in English news headlines. As a direct comparison, simile was used to add a visual aspect to understanding concepts in order to imply how two things that were not alike in most ways, were similar in one important aspect. Irony was employed for criticism in a humorous way in order to insult the government's economical policies. The use of paradox was to highlight a truth through using a sentence that was self contradictory in order to make the intention more memorable. Imagery was employed to evoke certain images and feelings in the mind in a way that it was both appealing and realistic to make the headline more tangible for readers, and finally by using the words which looked like the sounds they make, the headline employed onomatopoeia to make the reader hear the sounds as he reads. By describing the sound, the headline became more lively and appealing and directed attention to a particular concept. 


\section{Conclusion}

The main conclusion that can be drawn from this study is that the employment of wordplays strengthened the headline capabilities, facilitated discourse, met the economy of space, brought the social actors into focus or blurred their role with regard to particular actions, created the atmosphere of sympathy and empathy, exaggerated the certain concepts or faded the importance of others, created the image in the mind or made the reader hear the sounds in the strings of words which could create lasting impression on the readers' mind. The aforementioned claims should be concluded with stating that the findings for research question met the requirements for research objective.

The investigation of wordplay can contribute to the enhancement of awareness of the latent meaning of journalists' words within news headlines. The careful analysis of headlines containing wordplay uncovers rhetorical techniques. It uncovers principles and rules that are used for delivering language in a way that is impressive and persuasive. Examining the wordplay suggests that headline rhetoric is a significant contribution to understand the complexity and richness of journalistic texts in providing implied layers of meaning.

\section{References}

Ali, G. A. (2009). How Arab journalists translate English-Language newspaper headlines: Case studies in crosscultural understanding. Lewiston: The Edwin Mellen Press.

Bell, A. (1991). The language of news media. London: Blackwell.

Bonyadi, A., \& Samuel, M. (2013). Headlines in newspaper editorials: A contrastive study. Sage Open, 3(2), 1-10. doi: $10.1177 / 2158244013494863$

Dor, D. (2003). On newspaper headlines as relevance optimizers. Journal of Pragmatics, 35 (5), 695-721.

Iarovici, E., \& Amel, R. (1989). The strategy of the headline. Semiotica, 77(4), 441-459.

Leigh, J. H. (1994). The use of figures of speech in print ad headlines. Journal of Advertising, 23(2), 17-33.

Newmark, P. (1988). A textbook of translation. New York: Prentice hall.

Oaks, U. (2012). Working with the news media: A different kind of advocacy. NAFSA: Association of International Educators.

Sandell, R. G. (1977). Linguistic style and persuasion. London: Academic Press.

Saxena, S. (2006). Headline writing. New Delhi: SAGE publications India Pvt Ltd.

Smith, K. L. (2002). The translation of advertising texts: A study of English-language printed advertisements and their translations in Russian. (Unpublished doctoral dissertation). Department of Russian and Slavonic Studies: University of Sheffield.

Smith, K. (2006). Rhetorical figures and the translation of advertising headlines. Language and Literature, 15(2), 159182.

Ungerer, F. (2000). Introduction. In F. Ungerer (Ed.), English media texts past and present: Language and textual structure (pp. vii-xiv). Amsterdam: John Benjamins.

van Dijk, T. A. (1988). News analysis: Case studies of international and national news in the press. Hillsdale, New Jersey: Lawrence Erlbaum Associates, Publishers. 